\title{
An improved double loop control method for brushless DC motors
}

\author{
Yafei Zhang ${ }^{a}$, Jianfei Yang ${ }^{b}$, Huaren $\mathrm{Wu}^{\mathrm{c}}{ }^{\mathrm{C}}$, Xin Qiu ${ }^{\mathrm{d}}$, Jian Liu ${ }^{\mathrm{e}}$
}

School of Electrical and Automation Engineering, Nanjing Normal University, Nanjing 210000, China

azyfnjnu@163.com, b631056602@qq.com, '61031@njnu.edu.cn, d250163331@qq.com, e1079012096@qq.com

Keywords: Brushless DC motor, direct torque control, stator flux-linkage, switching table.

\begin{abstract}
The stator flux-linkage and torque double loop control strategy has been used in the traditional two-phase conducting brushless DC (BLDC) motor direct torque control (DTC) system. Based on the study of the control system, this paper presents a new space voltage vector switching table and new methods for the stator flux-linkage amplitude given and estimation. The improved control scheme obtained by the application of the methods and switching table to the double loop control system, can effectively control the stable operation of BLDC motors, and the scheme is verified by the experimental results.
\end{abstract}

\section{Introduction}

BLDC motors are widely used in aerospace, industrial control, automation, and other aspects [1, 3]. With the development of technology, the market demand for the performance of BLDC motors is becoming higher and higher. Researchers in the process of research found that direct torque control technology has the advantages of simple structure, fast torque response, and therefore be promoted in BLDC motor control $[4,5]$. Among them, the stator flux-linkage and torque double loop direct torque control strategy was first proposed and successfully applied $[6,8]$. Based on the analysis of the two-phase conducting BLDC motor direct torque control system, this paper presents an improved control scheme for BLDC motors. The difference between the improved and traditional control scheme are the space voltage vector switching table and the methods of the stator flux-linkage amplitude given and estimation. Further, the methods in improved control scheme do not contain stator resistance and integrator. The experimental results show that the improved scheme can effectively control the stable operation of BLDC motors.

\section{Theoretical analysis of double loop control method for BLDC motors}

Under ideal conditions, the voltage equation of BLDC motors is:

$$
\left[\begin{array}{l}
u_{\mathrm{a}} \\
u_{\mathrm{b}} \\
u_{\mathrm{c}}
\end{array}\right]=\left[\begin{array}{ccc}
R_{\mathrm{s}} & 0 & 0 \\
0 & R_{\mathrm{s}} & 0 \\
0 & 0 & R_{\mathrm{s}}
\end{array}\right]\left[\begin{array}{l}
i_{\mathrm{a}} \\
i_{\mathrm{b}} \\
i_{\mathrm{c}}
\end{array}\right]+\left[\begin{array}{ccc}
L-M & 0 & 0 \\
0 & L-M & 0 \\
0 & 0 & L-M
\end{array}\right] p\left[\begin{array}{c}
i_{\mathrm{a}} \\
i_{\mathrm{b}} \\
i_{\mathrm{c}}
\end{array}\right]+\left[\begin{array}{c}
e_{\mathrm{a}} \\
e_{\mathrm{b}} \\
e_{\mathrm{c}}
\end{array}\right]
$$

Where $u_{\mathrm{a}}, u_{\mathrm{b}}$ and $u_{\mathrm{c}}$ are the phase voltage of phase $\mathrm{a}, \mathrm{b}$ and $\mathrm{c}$, respectively. $i_{\mathrm{a}}, i_{\mathrm{b}}$ and $i_{\mathrm{c}}$ are the phase current of phase $\mathrm{a}, \mathrm{b}$ and $\mathrm{c}$, respectively. $e_{\mathrm{a}}, e_{\mathrm{b}}$ and $e_{\mathrm{c}}$ are the back-emf of phase $\mathrm{a}, \mathrm{b}$ and $\mathrm{c}$, respectively. $R_{\mathrm{s}}$ and $L$ are the each phase of the stator resistance and the self inductance, and $M$ is the mutual inductance between two phases.

The common used electromagnetic torque equation based on the three phases back-emf can be expressed as:

$$
T_{\mathrm{e}}=K\left(e_{\mathrm{a}} i_{\mathrm{a}}+e_{\mathrm{b}} i_{\mathrm{b}}+e_{\mathrm{c}} i_{\mathrm{c}}\right)
$$

Under the two-phase conducting control mode, the upper and lower switches of each bridge arm in the inverter may be shut down at the same time. Therefore, six digits are required to represent the conduction state of the six power switches, where 1 means on, 0 means off. The six effective states of 
the inverter, the corresponding voltage vector and six sectors are obtained by listing all the possible, as shown in Fig.1 $[9,10]$.

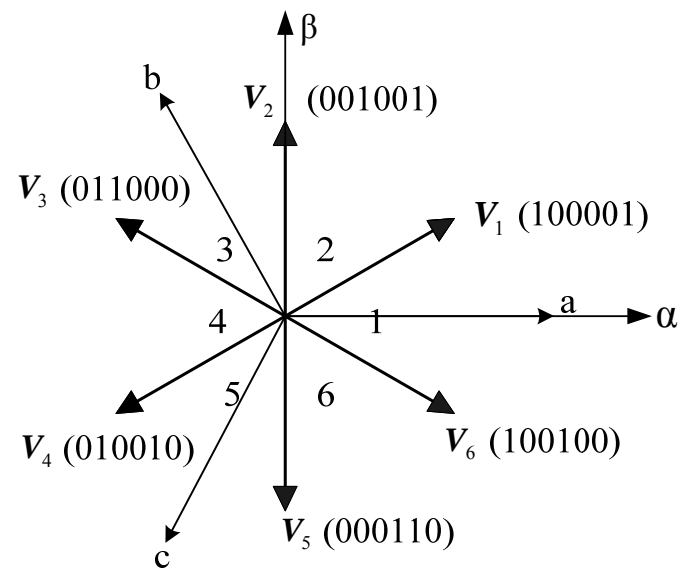

Fig. 1 Space voltage vector distribution and sector division

For example, when the rotor is located in the first sector, $V_{1}$ is used to increase the torque and stator flux-linkage, $\boldsymbol{V}_{2}$ is used to increase the torque and keep the stator flux-linkage unchanged, $\boldsymbol{V}_{3}$ is used to increase the torque and decrease the stator flux-linkage, $V_{4}$ is used to decrease the torque and stator flux-linkage, $\boldsymbol{V}_{5}$ is used to decrease the torque and keep the stator flux-linkage unchanged, $\boldsymbol{V}_{6}$ is used to increase the stator flux-linkage and decrease the torque, other sectors and so on. According to this principle and specific requirements, the space voltage vector switching table can be obtained, as shown in Table 1.

Table 1 Space voltage vector switching table

\begin{tabular}{c|c|c|c|c|c|c|c}
\hline \multirow{2}{*}{$\tau$} & \multirow{2}{*}{$\phi$} & \multicolumn{5}{|c}{ Sector $(\mathrm{S})$} \\
\cline { 3 - 8 } & & 1 & 2 & 3 & 4 & 5 & 6 \\
\hline \multirow{4}{*}{1} & 1 & $\boldsymbol{V}_{1}$ & $\boldsymbol{V}_{2}$ & $\boldsymbol{V}_{3}$ & $\boldsymbol{V}_{4}$ & $\boldsymbol{V}_{5}$ & $\boldsymbol{V}_{6}$ \\
\cline { 2 - 8 } & 0 & $\boldsymbol{V}_{2}$ & $\boldsymbol{V}_{3}$ & $\boldsymbol{V}_{4}$ & $\boldsymbol{V}_{5}$ & $\boldsymbol{V}_{6}$ & $\boldsymbol{V}_{1}$ \\
\cline { 2 - 8 } & -1 & $\boldsymbol{V}_{3}$ & $\boldsymbol{V}_{4}$ & $\boldsymbol{V}_{5}$ & $\boldsymbol{V}_{6}$ & $\boldsymbol{V}_{1}$ & $\boldsymbol{V}_{2}$ \\
\hline \multirow{4}{*}{0} & 1 & $\boldsymbol{V}_{6}$ & $\boldsymbol{V}_{1}$ & $\boldsymbol{V}_{2}$ & $\boldsymbol{V}_{3}$ & $\boldsymbol{V}_{4}$ & $\boldsymbol{V}_{5}$ \\
\cline { 2 - 8 } & 0 & $\boldsymbol{V}_{5}$ & $\boldsymbol{V}_{6}$ & $\boldsymbol{V}_{1}$ & $\boldsymbol{V}_{2}$ & $\boldsymbol{V}_{3}$ & $\boldsymbol{V}_{4}$ \\
\cline { 2 - 8 } & -1 & $\boldsymbol{V}_{4}$ & $\boldsymbol{V}_{5}$ & $\boldsymbol{V}_{6}$ & $\boldsymbol{V}_{1}$ & $\boldsymbol{V}_{2}$ & $\boldsymbol{V}_{3}$ \\
\hline
\end{tabular}

In Table $1, \tau$ and $\phi$ are the state parameters, and used to represent adjustments to the stator flux-linkage and electromagnetic torque, respectively. In each sector, if the actual torque is smaller than the commanded value ( $\tau=1)$, it indicates a requirement to increase the torque. If the actual torque is greater than the commanded value $(\tau=0)$, it indicates a requirement to decrease the torque. In addition, when the actual stator flux-linkage is smaller than the commanded value $(\phi=1)$, it indicates a requirement to increase the stator flux-linkage. When the actual stator flux-linkage is the same as the commanded value $(\phi=0)$, it indicates a requirement to keep the stator flux-linkage unchanged. When the actual stator flux-linkage is greater than the commanded value $(\phi=-1)$, it indicates a requirement to decrease the stator flux-linkage.

For a BLDC motor operating in the two-phase conducting mode, the components of the stator flux-linkage amplitude in the stationary $\alpha \beta$ reference frame can be expressed as:

$$
\begin{aligned}
& \psi_{\mathrm{s} \alpha}=L_{\mathrm{s}} i_{\mathrm{s} \alpha}+\psi_{\mathrm{r} \alpha}=L_{\mathrm{s}}\left|\boldsymbol{I}_{\mathrm{s}}\right| \cos \theta+\psi_{\mathrm{r}} \cos \theta_{\mathrm{r}} \\
& \psi_{\mathrm{s} \beta}=L_{\mathrm{s}} i_{\mathrm{s} \beta}+\psi_{\mathrm{r} \beta}=L_{\mathrm{s}}\left|\boldsymbol{I}_{\mathrm{s}}\right| \sin \theta+\psi_{\mathrm{r}} \sin \theta_{\mathrm{r}}
\end{aligned}
$$

Where $\psi_{\mathrm{r}}$ is the rotor flux-linkage amplitude and it is usually constant, $\theta_{\mathrm{r}}$ is the rotor position angle, 
$\theta$ is the angle between the $\alpha$ axis and phase synthesis current vector.

In addition, for the amplitude of the two conduction phase synthesis current vector, it is proportional to the value of the electromagnetic torque, as:

$$
\left|\boldsymbol{I}_{\mathrm{s}}\right|=\frac{1}{\sqrt{3} \mathrm{~K}}\left|T_{\mathrm{e}}\right|
$$

Where $\mathrm{K}$ is the ratio between the motor back-emf and the mechanical velocity. Substituting equation (4) into equation (3) gives:

$$
\begin{aligned}
& \psi_{\mathrm{s} \alpha}=L_{\mathrm{s}}\left|\boldsymbol{I}_{\mathrm{s}}\right| \cos \theta+\psi_{\mathrm{r} \alpha}=\frac{1}{2 \mathrm{~K}_{\mathrm{T}}} L_{\mathrm{s}}\left|T_{\mathrm{e}}\right| \cos \theta+\psi_{\mathrm{r}} \cos \theta_{\mathrm{r}} \\
& \psi_{\mathrm{s} \beta}=L_{\mathrm{s}}\left|\boldsymbol{I}_{\mathrm{s}}\right| \sin \theta+\psi_{\mathrm{r} \beta}=\frac{1}{2 \mathrm{~K}_{\mathrm{T}}} L_{\mathrm{s}}\left|T_{\mathrm{e}}\right| \sin \theta+\psi_{\mathrm{r}} \sin \theta_{\mathrm{r}}
\end{aligned}
$$

Then the amplitude of the stator flux-linkage can be calculated as:

$$
\left|\psi_{\mathrm{s}}\right|=\sqrt{\psi_{\mathrm{s} \alpha}^{2}+\psi_{\mathrm{s} \beta}^{2}}
$$

Therefore, equation (3) and (6) can be used to calculate the actual amplitude of the stator flux-linkage, so as to perform estimation of it. Substituting the given torque into equation (5) and (6) to calculate can obtain the corresponding given stator flux-linkage amplitude. While the torque given can be obtained through the PI regulator.

From equation (3) and (5) can be seen, the mathematical models of the stator flux-linkage estimation and given do not contain stator resistance and integrator. On the one hand, it can effectively control the impact of the stator resistance pressure drop and resistance change on flux-linkage calculation accuracy under the condition of low speed and temperature raise. On the other hand, it can avoid the integrator saturation problem caused by the DC offset.

\section{The improved double loop control scheme implementation}

Fig. 2 shows the block diagram for the two-phase conducting BLDC motor DTC double loop control system. As will be seen, the calculation accuracy of the rotor position angle directly affects the control effect of the whole system. Therefore, this system adopts photoelectric position sensor which can distinguish finer angle to accurately calculate the rotor position.

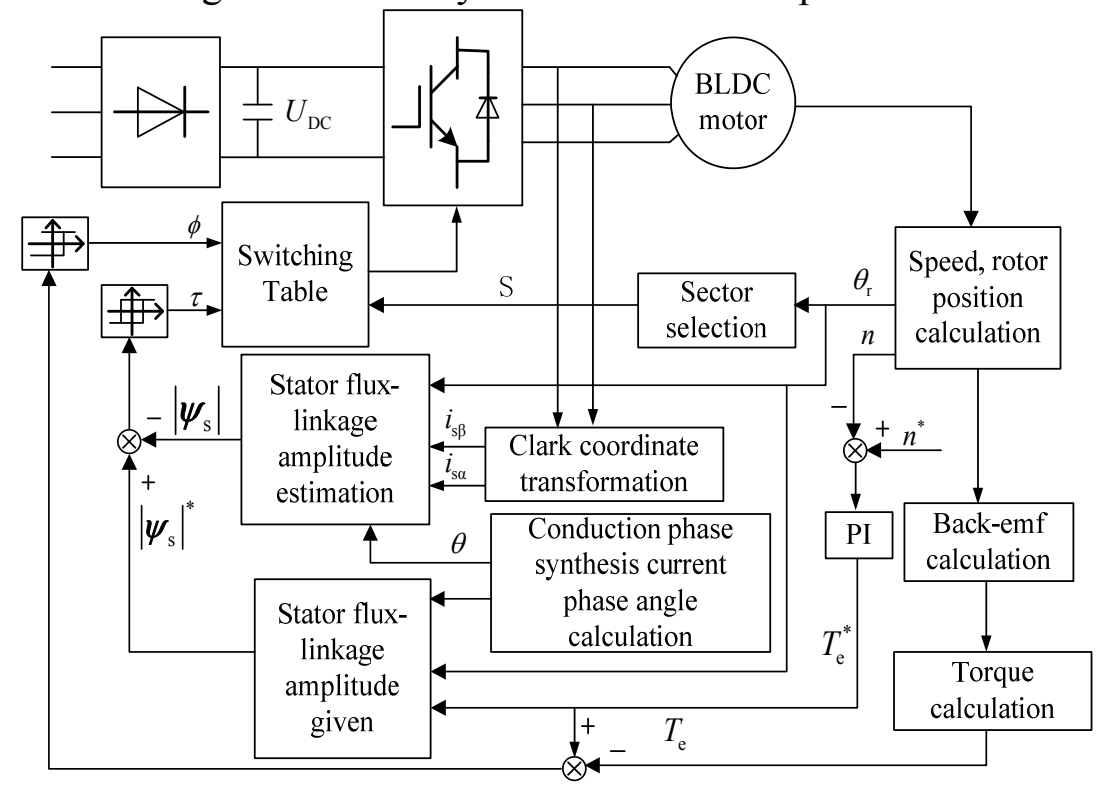

Fig. 2 The block diagram for DTC of BLDC motor

For the torque calculation of the improved control scheme, this paper adopts the above most common torque equation of BLDC motors to calculate the actual torque. Further, the torque calculation is based on the back-emf shape function. Therefore, for different BLDC motors with 
different non-ideal back-emf, substituting the corresponding actual back-emf shape function into the calculation can obtain the actual torque. For the stator flux-linkage amplitude given and estimation, this paper adopts the above equation (5) and (6) to calculate the given amplitude of the stator flux-linkage, and uses the equation (3) and (6) to realize the estimation of the stator flux-linkage.

The state parameters can be obtained by comparing the actual value of the torque and stator flux-linkage with the given value of that through the hysteresis comparator. Then combining with the sector and voltage vector switching table, the control system will select the correct voltage vector to act on BLDC motors, so as to realize the stable operation control of BLDC motors.

\section{Experimental results}

The improved double loop control scheme is validated by experiment for the BLDC motor, whose parameters are given in Table 2 . The given speed is $100 \mathrm{r} / \mathrm{min}$, and the load is $0.65 \mathrm{~N} . \mathrm{m}$. Under this condition, the experimental results are shown in Fig.3.

Table 2 Parameters of the BLDC motor

\begin{tabular}{|c|c|}
\hline Parameter & Value \\
\hline Rated Voltage $(\mathrm{V})$ & 36 \\
\hline $\operatorname{Rs}(\Omega)$ & 0.25 \\
\hline Stator Inductance $(\mathrm{mH})$ & 0.3 \\
\hline Rotor Flux $(\mathrm{Wb})$ & 0.0225 \\
\hline Pole Pairs & 8 \\
\hline
\end{tabular}

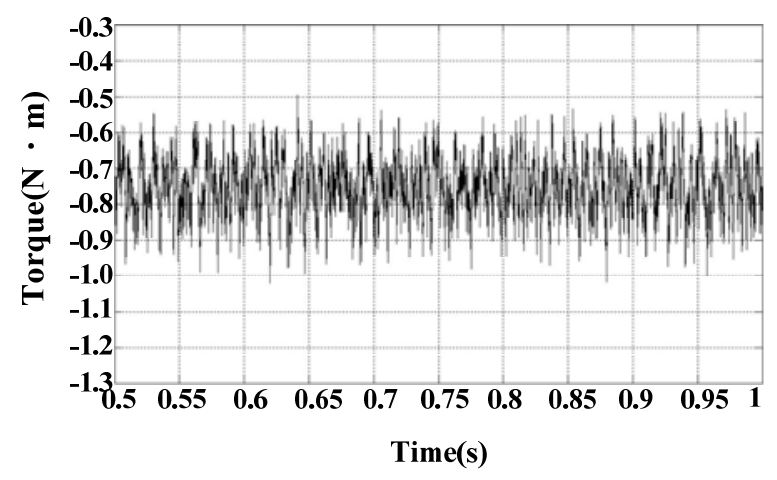

(a) Phase current

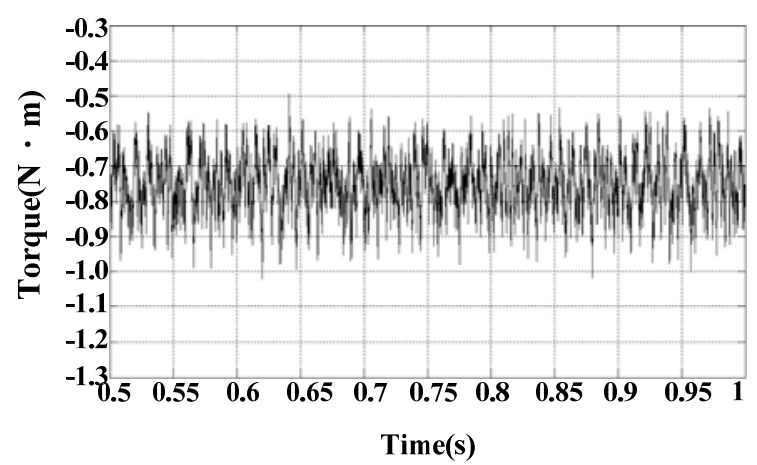

(c) Given stator flux-linkage amplitude

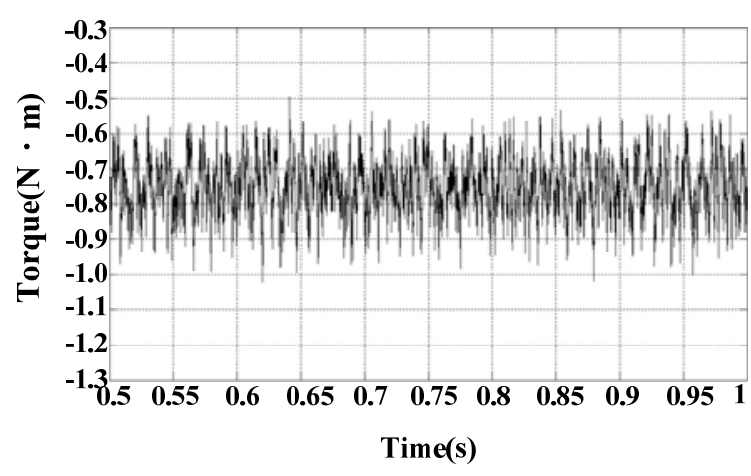

(b) Electromagnetic torque

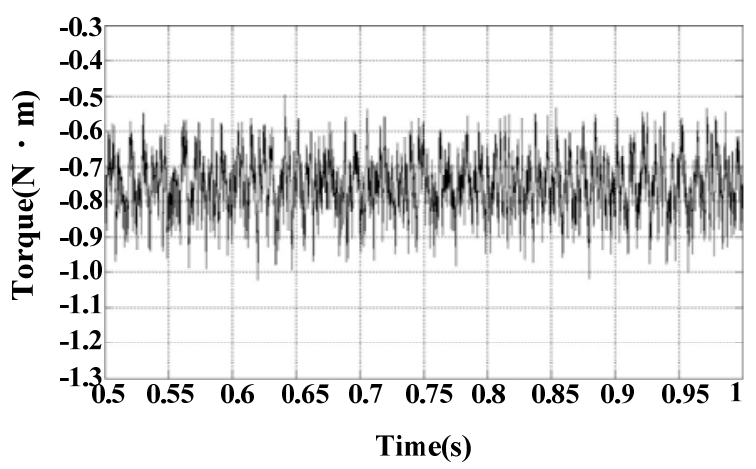

(d) Locus of stator flux-linkage

Fig. 3 Experimental results

As will be seen, the steady-state phase current waveform is shown in Fig.3(a). The current is $120^{\circ}$ conduction, and it shows that the BLDC motor operates in two-phase conducting mode. Fig.3(b) for the actual electromagnetic torque waveform, it fluctuates around 0.65 N.m. The torque ripple is bigger but it is stably controlled within a certain range. In addition, the ripple frequency of the electromagnetic torque is the same as that of the phase current. It indicates that the current is proportional to the torque in the two-phase conducting mode, which is consistent with the theoretical analysis. The given and estimated value of the stator flux-linkage are shown in Figs.3(c) and 3(d). 
Within a magnetic state, the given value of the stator flux-linkage increases from $0.022 \mathrm{~Wb}$ to 0.0232 $\mathrm{Wb}$. The change rule of the estimated value is consistent with the given value. It indicates that the actual flux-linkage strictly tracks the given flux-linkage. Based on the analysis of the above given method for the stator flux-linkage estimation, the actual stator flux-linkage locus should tend to a hexagon, as shown in Fig.3(d).

\section{Summary}

In this paper, the new space voltage vector switching table and the new methods of the stator flux-linkage amplitude given and estimation have been applied to the two-phase conduction BLDC motor direct torque control system. This is the main difference between the improved and the traditional control scheme. It has been shown that the improved scheme can effectively control the stable operation of BLDC motors. The correctness of theoretical analysis and the feasibility of the scheme have been validated by the experimental results.

\section{Acknowledgments}

The work was financially supported by "the National Natural Science Foundation of China", "the National Natural Science Foundation of Jiangsu Province" and "the Colleges and Universities in Jiangsu province natural science foundation of China". Project 61273243, 51407095 supported by National Natural Science Foundation of China. Project BK20151548 supported by National Natural

Science Foundation of Jiangsu Province. Project 15KJB470010 supported by Colleges and Universities in Jiangsu province natural science foundation of China.

\section{References}

[1] Shi Jian, Li Cai, Wang Xiaowei. Small inductance brushless DC motor sensorless control method for three-phase H bridge [J]. Proceedings of the CSEE, 2014, 12:1905-1911.

[2] Lin Hai, Yan Weisheng, Yang Ying, Lin Yang, Ma Wen. Brushless DC motor direct torque control system analysis [J]. Journal of Northwestern Polytechnical University, 2010,01:91-95.

[3] Yang Jianfei, Hu Yuwen. Permanent magnet synchronous motor direct torque control torque controller Settings. Proceedings of the CSEE, 2011, 31 (9) : 76-81.

[4] An Quntao, Sun Lizhi, Liu Chao, Sun Li. Flux control of brushless de motor direct torque control [J]. Proceedings of the CSEE, 2010, 12:86-92.

[5] Tan Jiancheng. Analysis of commutation torque ripple in brushless DC motor [J]. micromotors, 2011,06:1-6.

[6] Zhong L, Rahman M F, Hu Y W, et al. Analysis of direct torque control in permanent magnet synchronous motor drives[J]. IEEE Transactions on Power Electronics, 1997, 12(3):528-535.

[7] Giuseppe S Buja, Marian P Kazmierkowski. Direct torque control of PWM inverter-fed AC motors-a survey [J]. IEEE Transactions on Industrial Electronics, 2004,51(4): 744-757.

[8] Li Zhu, S.Z Jiang, J.Z Jiang, Z.Q Zhu, C.C Chan. A New Simplex Wave Winding Permanent-Magnet brushless DC Machine[J]. IEEE Transactions on Magnetics, 2011,47(1): 252-259.

[9] Yong Liu, Z.Q Zhu, David HoweDirect. Torque Control of brushless DC Drives With Reduced Torque Ripple[J]. IEEE Transactions on Industry Applications, 2005,41(2): 599-608.

[10] Xia Changliang, Fang Hongwei. Permanent magnet brushless DC motors and controls [J]. Journal of Electrotechnics, 2012 01:25-34. 